\title{
DESENVOLVIMENTO DE CAFEEIROS (Coffea arabica L.) ENXERTADOS SUBMETIDOS A DIFERENTES NÍVEIS DE REPOSIÇÃO DE ÁGUA
}

\author{
Coffea plant (Coffea arabica L.) growth with and \\ without grafting and irrigation levels at transplanting time
}

\author{
Alexandrino Lopes de Oliveira ${ }^{1}$, Rubens José Guimarães², Carlos Alberto Spaggiari Souza ${ }^{3}$, \\ Jacinto de Assunção Carvalho ${ }^{4}$, Antônio Nazareno Guimarães Mendes ${ }^{2}$, Rogério de Souza Guimarães ${ }^{5}$
}

\section{RESUMO}

Conduziu-se o presente trabalho com o objetivo de avaliar o desenvolvimento de diferentes cultivares de cafeeiro, enxertadas ou não, quando submetidas a diferentes níveis de reposição de água na fase de implantação da lavoura, na ausência de nematóides. O experimento foi conduzido em casa-de-vegetação no Setor de Cafeicultura do Departamento de Agricultura da Universidade Federal de Lavras, no período de março de 2002 a setembro de 2002. O delineamento estatístico utilizado foi em blocos casualizados, em esquema fatorial 4 × 2 × 5, envolvendo quatro cultivares: Acaiá Cerrado MG1474, Icatu Amarelo IAC-3282, IAPAR-59 e Rubi MG-1192, dois tipos de mudas (pé franco e enxertadas) e cinco níveis de reposição de água $(40 \%, 60 \%, 80 \%, 100 \%$ e $120 \%$ da evapotranspiração), com intervalos entre as irrigações de dois dias. Foram utilizadas 3 repetições com 3 plantas por parcela, perfazendo um total de 40 tratamentos, 120 parcelas e 360 plantas no experimento. As características avaliadas foram: diâmetro de caule $(\mathrm{mm})$, altura de plantas (cm), número de pares de folhas no ramo ortotrópico, número de ramos plagiotrópicos, massa seca das raízes (g) e massa seca da parte aérea (g). Concluiu-se que plantas oriundas de mudas, das cultivares estudadas, enxertadas sobre Apoatã IAC-2258, desenvolvem-se menos que as oriundas de pé franco na fase de implantação da lavoura, em solos isentos de nematóides; o desenvolvimento do sistema radicular da Apoatã IAC-2258 (porta-enxerto) não é alterado pelo uso de diferentes enxertos de porte alto ou baixo; quando não há limitação hídrica pronunciada, as plantas oriundas de mudas em pé franco desenvolvem-se mais que as plantas provenientes de mudas enxertadas; porém, em condições de déficit pronunciado, ambas têm seu desenvolvimento igualmente prejudicado no período de implantação da lavoura, em solos isentos de nematóides.

Termos para indexação: Café, cultivares, enxertia, irrigação.

\section{ABSTRACT}

This work had the objective of evaluating Coffea cultivars development, grafted and not grafted, in seedbed and their resistance to water application at crop implantation. The experiment was established in the seedbed and greenhouse at Coffee Sector of the Agronomy Department, Lavras Federal University (UFLA), from march 2002 to september 2002. The experimental design was a randomized block in factorial schemes. 4 × 2 x 5 in greenhouse, was used four cultivars Acaiá Cerrado MG-1474, Icatu Amarelo IAC3282, IAPAR-59 and Rubi-MG 1192 with and without grafting, and water addition at five levels (40\%, 60\%, 80\%, 100\% and 120\%) of field capacity two-day intervals. Three replications were used and plots were constituted by three plants, in a total of 40 treatments, 120 plots and 360 plants in trial. Plants were evaluated during the same period after planting in the pots. The characteristics evaluated were: stem diameter $(\mathrm{mm})$, seedling and plant height $(\mathrm{cm})$, number of leaf pairs in orthotrophic branch, number of leaf pairs in plagiotrophic branch, root dry weight (g), above ground dry weight (g). All Coffea cultivars grafted in Apoatã IAC-2258 has less development than when not grafted. The development Apoatã IAC-2258 root system is not altered by other cultivars grafting. With sufficient water availability seedling without grafting has bether development than when graftd.

Index terms: Coffea, cultivars, grafting, irrigation.

(Recebido para publicação em 23 de outubro de 2003 e aprovado em 26 de agosto de 2004)

\section{INTRODUÇÃO}

O sucesso na atividade cafeeira depende da adoção de alternativas de manejo para a redução de custos, aumento da produtividade e melhoria da qualidade do produto. Por se tratar de uma cultura perene, é de suma importância que a implantação da lavoura seja realizada com mudas sadias, bem desenvolvidas e de materiais genéticos com resistência a pragas e doenças.

\footnotetext{
1. Engenheiro Agrônomo, Mestre em Agronomia, Universidade Federal de Lavras/UFLA, Caixa Postal 3037 - $37200-000$ - Lavras, MG. Bolsista de Especialização CBP\&D/Café - EMBRAPA Café/UFLA alexandrinoo@bol.com.br

2. Professor adjunto, Departamento de Agricultura/UFLA, rubensjg@ufla.br Fone: (0XX35) 3829-1336.

3. Engenheiro Agrônomo, Doutor em Agronomia, Pesquisador CEPLAC/ES, Caixa Postal 102.

4. Professor adjunto, Departamento de Engenharia/UFLA.

5. Estudante de Graduação em Agronomia.
} 
Atualmente, são poucas as opções de cultivares comerciais que apresentam, numa mesma planta, características de resistência a pragas e doenças da parte aérea e sistema radicular do cafeeiro. A ocorrência generalizada de nematóides em grande parte da área plantada de café no Brasil poderá inviabilizar a cafeicultura em regiões tradicionalmente produtoras de café, em razão da falta de resistência dos materiais genéticos existentes. Por outro lado, alguns materiais de Coffea canephora Pierre vêm evidenciando resistência aos nematóides dos gêneros $\mathrm{Me}$ loidogyne e Pratylenchus (COSTA et al., 1991). A cultivar que tem apresentado resistência aos nematóides Meloidogyne spp (no Brasil) é a Apoatã IAC-2258 (FAZUOLI, 1986) e a Pratylenchus (na Guatemala) é a Robusta (VILLAIN et al., 1995).

Uma das opções para se obter numa mesma planta resistência ou tolerância a pragas e doenças de parte aérea e de sistema radicular a curto prazo de forma e eficiente seria por meio da enxertia hipocotiledonar (SOUZA et al., 2002), incorporando o sistema radicular de Apoatã IAC-2258, que, segundo Fazuoli et al. (1978), apresenta tolerância aos fitonematóides Meloidogyne exigua e Meloidogyne incognita; como enxerto, cultivares de Coffea arabica que apresentam resistência às doenças e pragas da parte aérea (Hemileia vastatrix Berk. \& Br. e Leucoptera cofeella) (MATIELLO et al., 2000).

Fazuoli et al. (1983), em trabalho de campo, avaliaram o desenvolvimento de plantas de cafeeiro enxertadas em regiões infestadas por Meloidogyne incognita, verificando aumentos de altura, diâmetro de copa e de produção, em comparação com as plantas não enxertadas. Essa vantagem em área com nematóides também foi confirmada por Costa et al. (1991), que verificaram produção de 26,3 sacas/ha de café beneficiado nas plantas da cultivar Mundo Novo enxertadas em portaenxertos resistentes de $C$. canephora, contra apenas 5,7 sacas/ha de café beneficiado para a cultivar Mundo Novo sem enxertia.

Segundo Villain et al. (1995), a utilização de porta-enxerto resistente de $C$. canephora mostrou-se altamente produtiva em área com alta população de Pratylenchus spp, na Guatemala, onde a produtividade média da área com plantas enxertadas foi de 45,6 sacas/ha de café com pergaminho. Nas mesmas condições, as plantas em pé-franco produziram apenas 10 sacas/ha de café com pergaminho. Neste trabalho, concluiu-se também que o efeito de controle químico na redução da pressão de nematóides nos tratamentos com plantas não enxertadas ocorreu apenas no primeiro ano após o plantio.
Uma outra vantagem da utilização de mudas de cafeeiro enxertadas é que essas podem contribuir com o aumento de produtividade, mesmo em áreas isentas de nematóides, o que foi verificado por Fahl et al. (1998). Esses autores avaliaram as características de crescimento, nutrição mineral e produção de plantas de cafeeiros enxertados e conduzidos em solos com ausência de nematóides durante quatro colheitas, concluindo que a utilização de genótipos de C. canephora e de C. congensis como portaenxertos de C. arabica conferiu maior desenvolvimento da parte aérea das plantas, sobretudo na cultivar Catuaí. Os mesmos autores verificaram também que as plantas enxertadas apresentaram maiores teores foliares de potássio e menores teores foliares de manganês do que as plantas não enxertadas, e que, por meio de análise global, a enxertia aumentou a produção do café, com maior efeito na cultivar Catuaí. No entanto, Figueiredo Júnior (1999) não verificou vantagens no desenvolvimento inicial de plantas de cafeeiro de $C$. arabica enxertadas em C. canephora (Apoatã IAC-2258) e cultivadas em áreas com e sem a presença de nematóides Meloidogyne exigua.

Embora existam trabalhos mostrando os efeitos positivos da enxertia, mesmo em áreas isentas de nematóides, não há na literatura trabalhos que comparem as plantas enxertadas e em pé franco, quando submetidas a diferentes níveis de reposição de água na fase de implantação da lavoura. Esse tipo de comparação poderia inferir o comportamento do sistema radicular da Apoatã IAC-2258 quando usada como porta-enxerto de C. arabica, em condições de maior ou menor disponibilidade de água no solo. Nos trabalhos de pesquisas, tem-se demonstrado que o cafeeiro tem boa resposta à irrigação na sua fase vegetativa e reprodutiva (GERVÁSIO, 1998; VILELLA, 2001). No entanto, a utilização de portaenxertos que se desenvolva mais no perfil do solo poderá conferir maior utilização do potencial genético de produção nas cultivares de C. arabica em anos que apresentem déficit hídrico acentuado.

Com o presente trabalho teve-se como objetivo avaliar o desenvolvimento de diferentes cultivares de cafeeiro, enxertadas ou não, quando submetidas a diferentes níveis de reposição de água na fase de implantação da lavoura, na ausência de nematóides.

\section{MATERIAL E MÉTODOS}

O experimento foi conduzido em casa-devegetação no Setor de Cafeicultura do Departamento de Agricultura da Universidade Federal de Lavras (UFLA), no período de março a setembro de 2002. O município de Lavras está localizado no Estado de Minas Gerais a 
$21^{\circ} 14$ ' $06^{\prime \prime}$ de latitude sul, $45^{\circ} 00^{\prime} 00^{\prime}$ de longitude oeste e altitude de $910 \mathrm{~m}$. O clima da região, segundo a classificação de Köppen, é do tipo Cwa, temperado úmido, com verão quente e inverno seco (OMETTO, 1981). A temperatura média do mês mais quente é de $22,1^{\circ} \mathrm{C}$ e a do mês mais frio é de $15,8^{\circ} \mathrm{C}$; a temperatura media anual é de $19,4^{\circ} \mathrm{C}$ e a umidade relativa média anual é de 76,2\% (BRASIL, 1992).

Para o porta-enxerto, foi utilizada a cultivar Apoatã, linhagem IAC-2258 (C. canephora), por apresentar resistência aos nematóides Meloidogyne exigua, Meloidogyne incognita e Meloidogyne paranaensis e por apresentar também, segundo Thomaziello et al. (2000), vigoroso e abundante sistema radicular, produzindo sementes graúdas e de bom aspecto.

O delineamento experimental utilizado foi em blocos casualizados, em esquema fatorial $4 \times 2 \times 5$, sendo quatro cultivares de C. arabica (Acaiá Cerrado MG-1474, Icatu Amarelo IAC-3282, IAPAR-59 e Rubi MG-1192), dois tipos de mudas (pé franco e enxertadas em Apoatã IAC-2258) e cinco níveis de reposição de água (40\%, 60\%, 80\%, 100\% e 120\% ). Foram utilizadas três repetições com três plantas por parcela, perfazendo um total de 40 tratamentos e 120 parcelas e 360 plantas. Os dados foram analisados pelo programa estatístico Sisvar (FERREIRA, 2000).

As mudas, quando se encontravam com 5 a 6 pares de folhas, foram plantadas em vasos de volume de 10 litros, tendo cada vaso recebido 8 litros da mistura de terra de subsolo com esterco de curral. Para a utilização de esterco de curral, correção da acidez, aplicação de fósforo e adubação de cobertura, foram seguidas as recomendações da Comissão de Fertilidade do Solo do Estado de Minas Gerais (CFSEMG, 1999).

Após o plantio das mudas, todos os vasos foram irrigados diariamente durante os primeiros trinta dias, de forma a propiciar boas condições de "pegamento" das mudas. A partir desse momento iniciou-se a aplicação das diferentes lâminas de reposição de água nos tratamentos, com turno de rega a cada dois dias, durante seis meses.

Os volumes de água de irrigação, representando os tratamentos de reposição de água, foram obtidos a partir de um percentual da quantidade de água evapotranspirada (consumida) pela testemunha (100\% de reposição). A evapotranspiração da planta foi determinada por meio do balanço hídrico, em que ET = I - D, sendo ET a evapotranspiração (volume de água consumido), I o volume de água aplicado e D o vo- lume drenado. A partir desse valor, foi obtida a quantidade de água de reposição para cada tratamento, aplicando-se nos vasos apenas o percentual desse volume, relativo a cada tratamento, conforme citado por Carvalho et al. (2001). O controle da irrigação foi realizado para cada cultivar e tipo de mudas, o que resultou em oito controles de irrigação.

As características avaliadas foram: a) diâmetro de caule (medido em milímetros abaixo da folha cotiledonar); b) número de pares de folhas no ramo ortotrópico (contaram-se as folhas com comprimento maior ou igual $2,5 \mathrm{~cm}$ ); c) altura de plantas (medida em centímetros a partir do colo da planta até o meristema apical); d) número de ramos plagiotrópicos (considerados apenas os ramos que apresentavam pelo menos um par de folhas com comprimento maior ou igual a 2,5 cm); e) massa seca das raízes e massa seca da parte aérea (em gramas). Para a obtenção da massa seca, as plantas foram retiradas dos vasos, cortadas na região do colo e lavadas em água corrente; em seguida, foram colocadas em sacos de papel e levadas a estufas com circulação forçada de ar a $65^{\circ} \mathrm{C}$, até peso constante.

\section{RESULTADOS E DISCUSSÃO}

Nota-se, na Tabela 1, que as plantas provenientes de mudas em pé franco apresentaram maior diâmetro de caule e número de pares de folhas no ramo ortotrópico, independente da cultivar e nível de irrigação utilizados. Esses resultados concordam com os obtidos por Figueiredo Júnior (1999), que também verificou superioridade das plantas em pé franco em condição de campo.

TABELA 1 - Valores médios de diâmetro de caule (mm) e número de pares de folhas no ramo ortotrópico por planta de mudas em pé franco e enxertadas, independente da cultivar e irrigação utilizada, aos sete meses após seu plantio em vasos.

\begin{tabular}{lcc}
\hline $\begin{array}{c}\text { Tipos de } \\
\text { Mudas }\end{array}$ & $\begin{array}{c}\text { Diâmetro de } \\
\text { Caule (mm) }\end{array}$ & $\begin{array}{c}\text { No de Pares de Folhas } \\
\text { no Ramo Ortotrópico }\end{array}$ \\
\hline Pé franco & $9,6 \mathrm{a}$ & $14,1 \mathrm{a}$ \\
Enxertadas & $7,8 \mathrm{~b}$ & $13,1 \mathrm{~b}$ \\
\hline CV(\%) & 21,5 & 8,5 \\
\hline
\end{tabular}

Médias seguidas de mesma letra nas linhas não diferem entre si, pelo teste de Scott-Knott, a $1 \%$ de probabilidade. 
São apresentados na Figura 1 os resultados para número de pares de folhas do ramo ortotrópico, os quais apresentaram diferença significativa $(\mathrm{P}<0,01)$ pelo teste F. Os resultados apresentaram um ajuste linear quadrático com efeito significativo $(\mathrm{P}<0,01)$ e $\mathrm{R}^{2}$ também altamente significativo.

Percebe-se que, no nível de reposição de água de $40 \%$, obtiveram-se 10,6 pares de folhas e 15,1 no nível de $120 \%$, evidenciando um aumento da ordem de 42,4\%, o que demonstra a importância da disponibilidade de água no solo para o desenvolvimento inicial da cultura, como observado por Gervásio (1998). Nessa fase crítica da cultura no pós-plantio, a ocorrência de um veranico pode inibir o crescimento das plantas e, conseqüentemente, produzir menor número de folhas no ramo ortotrópico.

Na Tabela 2 são apresentados os resultados de altura de plantas para cada cultivar com e sem enxertia. Nota-se que houve diferença significativa para todas as cultivares, prevalecendo sempre a superioridade das plantas provenientes de mudas em pé franco, sendo essas diferenças equivalentes a 14,9\%, 14,8\%, 16,9\% e $18,8 \%$, respectivamente para cada cultivar.

O menor desenvolvimento das plantas enxertadas pode estar associado ao efeito do estresse provocado pela prática da enxertia ou até mesmo ao menor desenvolvimento do sistema radicular da Apoatã IAC-2258, quando utilizada como porta-enxerto nas cultivares de C. arabica até essa fase de desenvolvimento das plantas.

TABELA 2 - Resultados de altura de plantas no desdobramento de cultivar para cada tipo de mudas, sete meses após seu plantio em vasos.

\begin{tabular}{lcc}
\hline \multicolumn{1}{c}{ Cultivares } & Pé Franco & Enxertadas \\
\hline Acaia Cerrado MG-1474 & $75,3 \mathrm{a}$ & $64,1 \mathrm{~b}$ \\
IAPAR-59 & $42,0 \mathrm{a}$ & $35,8 \mathrm{~b}$ \\
Icatu Amarelo IAC-3282 & $77,4 \mathrm{a}$ & $64,3 \mathrm{~b}$ \\
Rubi MG-1192 & $44,7 \mathrm{a}$ & $36,3 \mathrm{~b}$ \\
\hline CV(\%) & \multicolumn{2}{c}{5,85} \\
\hline
\end{tabular}

Médias seguidas de mesma letra nas linhas não diferem entre si, pelo teste de Scott-Knott, a $1 \%$ de probabilidade.

Na Figura 2 são apresentados os resultados de número de ramos plagiotrópicos de plantas oriundas de mudas em pé franco e enxertadas aos sete meses após o plantio em vasos em cinco níveis de reposição de água (\%), independente da cultivar utilizada. Os dados foram analisados pelo teste $\mathrm{F}$ e apresentaram diferença significativa $(\mathrm{P}<0,01)$. No desdobramento de irrigação para cada tipo de muda, verificou-se um ajuste linear quadrático com efeito significativo $(\mathrm{P}<0,01)$ e $\mathrm{R}^{2}$ também altamente significativo para os dois tipos de mudas. Nas plantas em pé franco, o máximo número de ramos plagiotrópicos foi obtido até o nível de reposição de água de $107,4 \%$, correspondendo a 12,5 ramos plagiotrópicos por planta, ao passo que para as plantas enxertadas, o número de ramos plagiotrópicos foi crescente até o nível de 101,8\%, com 12,6 ramos plagiotrópicos por planta. Os melhores resultados foram sempre os das plantas provenientes de mudas em pé franco. Esses resultados são semelhantes aos observados por Figueiredo Júnior (1999), que também verificou menor número de ramos plagiotrópicos de plantas de C. arabica enxertadas em Apoatã IAC-2258 em condição de campo.

Na Tabela 3 são apresentados os valores médios da massa seca de raízes de três plantas no desdobramento tipo de mudas para cada cultivar e de cultivares para cada tipo de muda. Observa-se, de forma geral, que quanto ao tipo de mudas para cada cultivar, os melhores resultados foram verificados nas plantas provenientes de mudas em condição de pé franco, possivelmente pelo fato de essas plantas não terem passado pelo estresse da enxertia. Pode também significar que o sistema radicular da Apoatã IAC-2258, quando utilizada como portaenxerto de $C$. arabica, não contribui para o aumento de massa seca de raízes das plantas até sete meses após seu plantio.

Quanto à análise entre as cultivares para cada tipo de muda, observa-se efeito significativo apenas para o tipo de mudas pé franco, com maiores valores de massa seca de raízes nas cultivares Icatu Amarelo IAC-3282 e Rubi MG1192.

Quando se observa a massa seca de raízes das plantas provenientes de mudas enxertadas, nota-se que não houve diferença significativa entre as cultivares. Por se tratar do sistema radicular apenas do Apoatã IAC-2258, pode-se dizer que, até o período de sete meses do plantio da cultura, o porte das cultivares não interfere na quantidade de massa seca das raízes.

Encontram-se na Tabela 4 os valores médios da massa seca de raízes (g) no desdobramento de tipo de mudas para cada nível de reposição de água. Podese verificar que não houve diferença significativa entre os tipos de mudas apenas no nível de irrigação de $40 \%$. Nos demais níveis de reposição de água, houve a tendência, até então observada, da superioridade das 
plantas oriundas de mudas em pé franco em relação às enxertadas. Possivelmente, a ausência de diferença entre mudas enxertadas e de pé franco em condições de $40 \%$ de reposição de água deve-se ao fato de a limitação hídrica ter inibido o desenvolvimento do sistema radicular das plantas oriundas dos dois tipos de mudas (pé franco e enxertadas). Mais uma vez, as plantas oriundas de mudas enxertadas não se desenvolvem tão bem quanto as oriundas de mudas em pé franco, possivelmente pelo estresse causado pela enxertia ou, ainda, por uma suposta incompatibilidade entre enxertos e porta-enxertos utilizados.

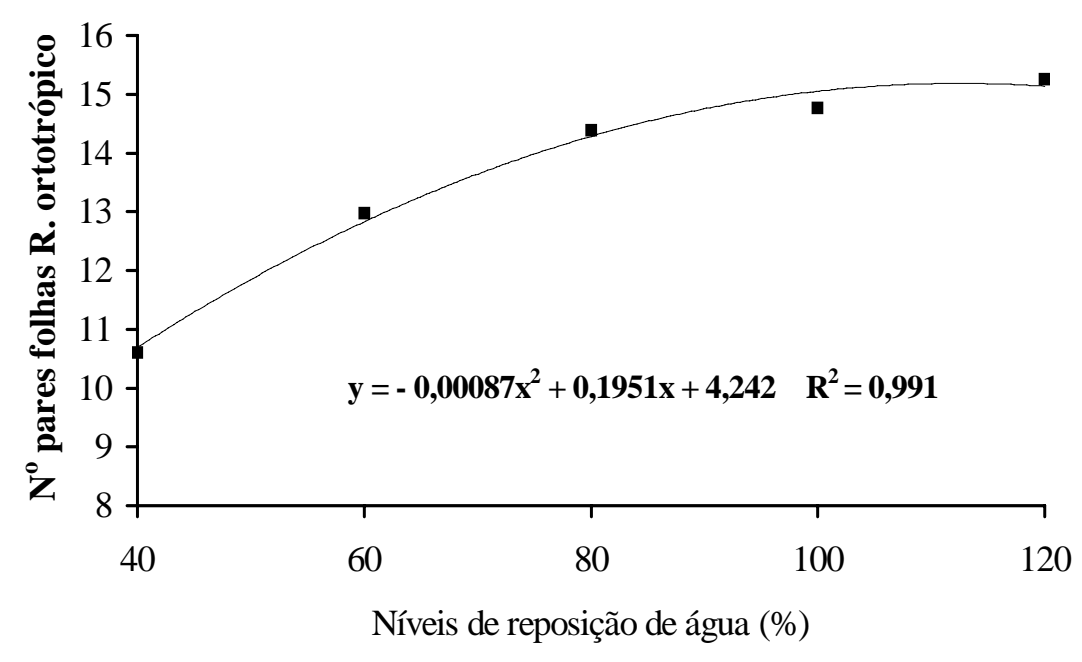

FIGURA 1 - Número de pares de folhas do ramo ortotrópico por planta de cafeeiro em cinco níveis de irrigação, independente da cultivar ou do tipo de muda utilizada, aos sete meses após o plantio.

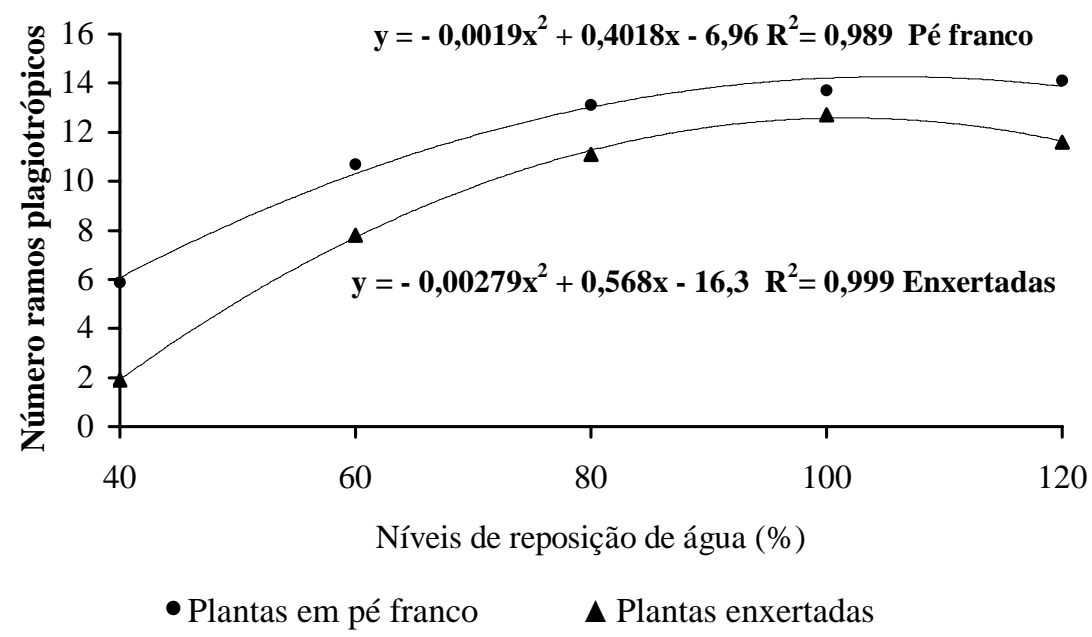

FIGURA 2 - Número de ramos plagiotrópicos por planta para cada nível de reposição de água (\%) e tipo de muda, sete meses após seu plantio em vasos. 
Na Figura 3 são apresentados os resultados de massa seca de raízes das plantas oriundas de mudas em pé franco e enxertadas aos sete meses após o plantio em vasos em cinco níveis de reposição de água (\%), independente da cultivar utilizada. Os dados foram analisados pelo teste
F e apresentaram diferença significativa $(\mathrm{P}<0,01)$. No desdobramento de níveis de irrigação dentro de cada tipo de plantas (pé franco e enxertadas), verificou-se um ajuste linear quadrático com efeito significativo $(\mathrm{P}<0,01)$ e $\mathrm{R}^{2}$ também altamente significativo para os dois tipos de plantas.

TABELA 3 - Valores da massa seca de raízes de três plantas no desdobramento tipo de mudas para cada cultivar e de cultivares para cada tipo de mudas.

\begin{tabular}{lcccc}
\hline \multirow{2}{*}{ Tipos de Mudas } & Acaiá Cerrado MG-1474 & IAPAR-59 & $\begin{array}{c}\text { Icatu Amarelo IAC- } \\
\mathbf{3 2 8 2}\end{array}$ & Rubi MG 1192 \\
\hline Pé franco & 34,28 a B & 33,48 a B & 43,09 a A & 41,79 a A \\
Enxertadas & 23,70 b A & 24,78 b A & 26,24 b A & 23,73 b A \\
\hline CV(\%) & & \multicolumn{2}{c}{15,4} \\
\hline
\end{tabular}

Médias seguidas de mesma letra minúscula nas colunas e maiúscula nas linhas não diferem entre si, a $1 \%$ de probabilidade, pelo teste de Scott-Knott.

TABELA 4 - Valores médios da massa seca de raízes de três plantas (g) no desdobramento de tipo de mudas para cada nível de reposição de água (\%).

\begin{tabular}{lccccc}
\hline \multirow{2}{*}{ Tipos de mudas } & \multicolumn{5}{c}{ Níveis de reposição de água (\%) } \\
\cline { 2 - 6 } & $\mathbf{4 0}$ & $\mathbf{6 0}$ & $\mathbf{8 0}$ & $\mathbf{1 0 0}$ & $\mathbf{1 2 0}$ \\
\hline Pé franco & $9,6 \mathrm{a}$ & $21,3 \mathrm{a}$ & $43,6 \mathrm{a}$ & $58,5 \mathrm{a}$ & $57,8 \mathrm{a}$ \\
Enxertadas & $5,8 \mathrm{a}$ & $12,5 \mathrm{~b}$ & $29,5 \mathrm{~b}$ & $37,7 \mathrm{~b}$ & $37,6 \mathrm{~b}$ \\
\hline CV $(\%)$ & & & 15,4 & \\
\hline
\end{tabular}

Médias seguidas de mesma letra nas colunas, para cada nível de reposição de água, não diferem entre si, a $1 \%$ de probabilidade, pelo teste de Scott-Knott.

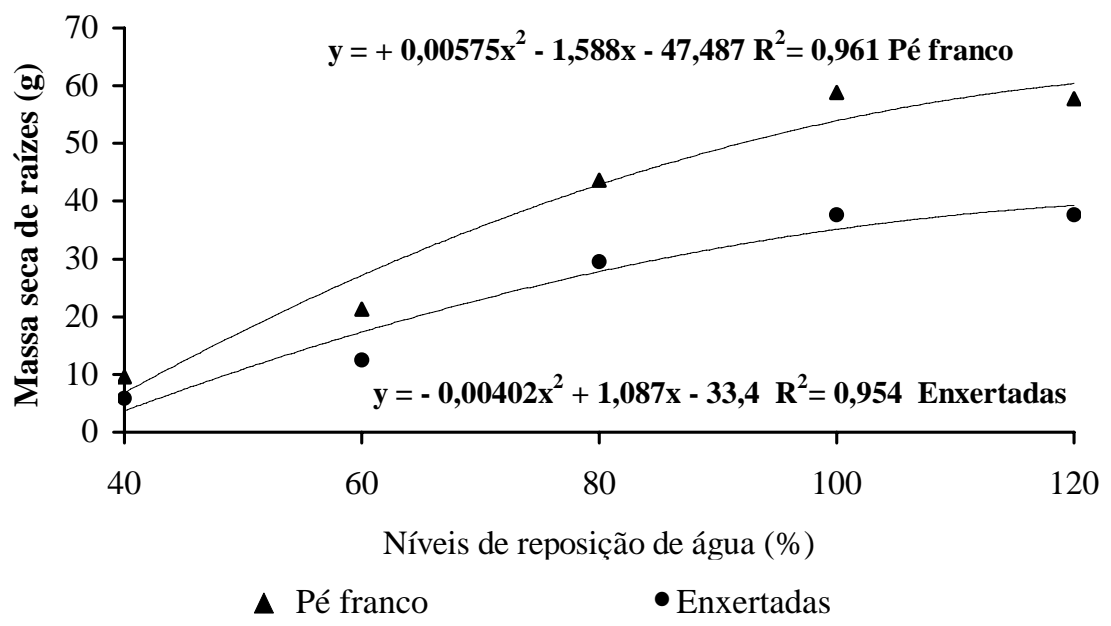

FIGURA 3 - Valores médios da massa seca de raízes de três plantas no desdobramento irrigação dentro de cada nível de tipo de muda.

Ciênc. agrotec., Lavras, v. 28, n. 6, p. 1291-1298, nov./dez., 2004 
Nota-se, pela Figura 3, que há uma tendência de maior massa seca de raízes nas plantas à medida que se aumentaram os níveis de reposição de água, e em todos os níveis, a massa seca de raízes foi maior nas plantas provenientes de mudas em pé franco. Verifica-se também a tendência de que quanto menor a limitação hídrica, maior é a diferença de acúmulo de massa seca de raízes entre as plantas em pé franco e enxertadas, reforçando a afirmativa de que um maior déficit hídrico (40\%) tenha igualado o desenvolvimento radicular das plantas oriundas dos dois tipos de mudas (pé franco e enxertadas), como comentado na Tabela 4.

Na Figura 4 são apresentados os resultados de massa seca da parte aérea de três plantas de café oriundas de mudas em pé franco e enxertadas aos sete meses após o plantio em vasos em cinco níveis de reposição de água (\%). Os dados foram analisados pelo teste $\mathrm{F}$ e apresentaram diferença significativa $(\mathrm{P}<0,05)$. No desdobramento de níveis de irrigação para cada cultivar em pé franco e enxertada, verificou-se um ajuste linear quadrático com efeito significativo $(\mathrm{P}<0,01)$ e $\mathrm{R}^{2}$ também altamente significativo para os dois tipos de plantas.

Observa-se maior massa seca da parte aérea à medida que foi aumentando os níveis de reposição de água. Houve, de forma geral, a predominância das plantas oriundas de mudas em pé franco em relação às plantas provenientes de mudas enxertadas em todos os níveis de reposição de água. Esses resultados demonstram haver uma relação entre o desenvolvimento do sistema radicular e a parte aérea, pois, como foi verificado na Figura 3, as plantas de café em pé franco também apresentaram maior massa seca de raízes. $\mathrm{O}$ melhor desenvolvimento das plantas nos maiores níveis de reposição de água também foi verificado por Gervásio (1998) que, em trabalho com a cultivar Icatu Amarelo IAC3282 em condição de pé franco, verificou maior desenvolvimento nas maiores lâminas de reposição de água.

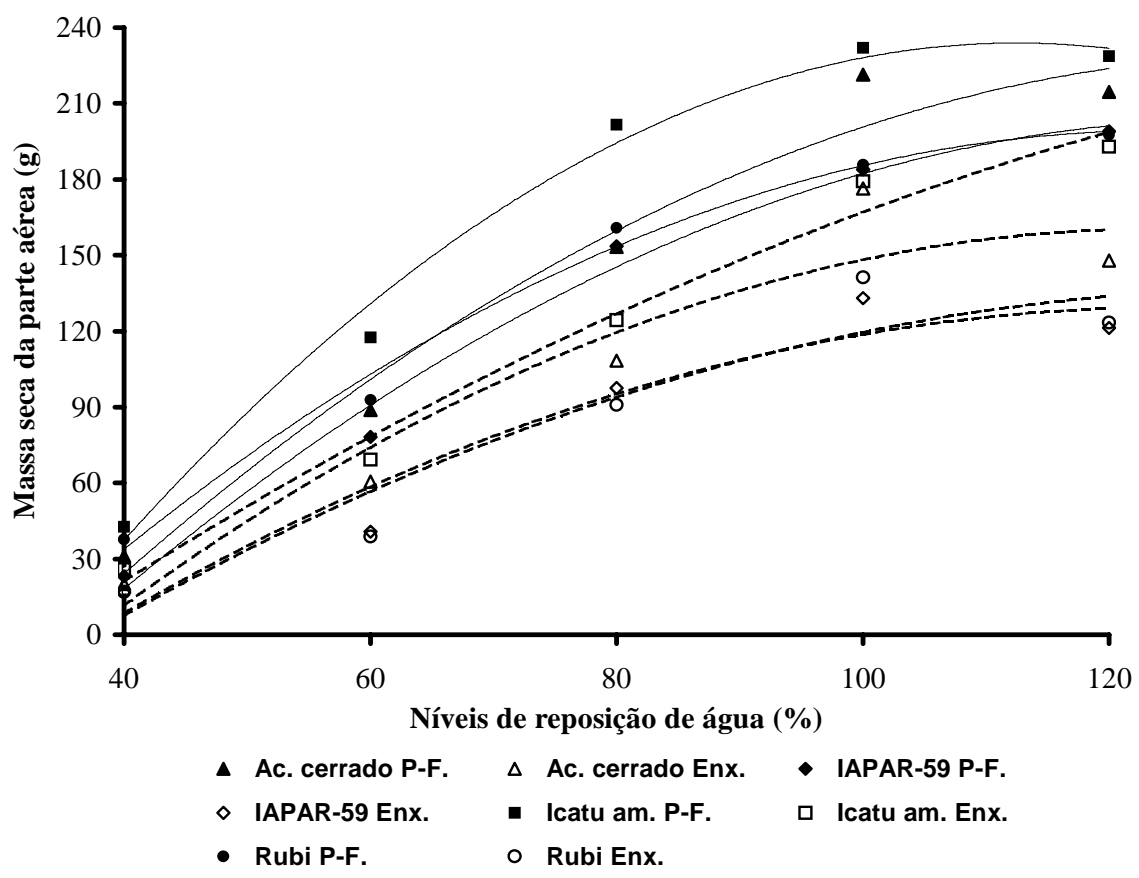

$Y=-183,03+6,07 x-0,022 x^{2} R^{2}=0,972$ Acaiá Cerrado MG-1474 pé franco
$Y=-163,7+5,22 x-0,021 x^{2} R^{2}=0,918$ Acaiá Cerrado MG-1474 enxertado
$Y=-180,7+5,86 x-0,022 x^{2} R^{2}=0,989$ IAPAR-59 pé franco
$Y=-131,3+4,15 x-0,0165 x^{2} R^{2}=0,937$ IAPAR-59 enxertado
$Y=-239,8+8,42 x-0,037 x^{2} R^{2}=0,989$ Icatu Amarelo IAC-3282 pé franco
$Y=-118,5+3,91 x-0,0106 x^{2} R^{2}=0,986$ Icatu Amarelo IAC-3282 enxertado
$Y=-160,4+5,78 x-0,023 x^{2} R^{2}=0,991$ Rubi MG-1192 pé franco
$Y=-125,2+3,9 x-0,014 x^{2} R^{2}=0,913$ Rubi MG-1192 enxertado

FIGURA 4 - Massa seca da parte aérea de três plantas (g) no desdobramento de irrigação dentro de cultivares e tipos de mudas, aos sete meses após seu plantio em vasos. 


\section{CONCLUSÕES}

Plantas oriundas de mudas, das cultivares estudadas, enxertadas sobre Apoatã IAC-2258 desenvolvem-se menos que as oriundas de pé franco na fase de implantação da lavoura, em solos isentos de nematóides.

O desenvolvimento do sistema radicular da Apoatã IAC-2258 (porta-enxerto) não é alterado pelo uso de diferentes enxertos de porte alto ou baixo.

Quando não há limitação hídrica pronunciada, as plantas oriundas de mudas em pé franco desenvolvemse mais que as plantas provenientes de mudas enxertadas; porém, em condições de déficit pronunciado, ambas têm seu desenvolvimento igualmente prejudicado no período de implantação da lavoura, em solos isentos de nematóides.

\section{REFERÊNCIAS BIBLIOGRÁFICAS}

BRASIL. Ministério da Agricultura. Normas Climatológicas: 1960-1990. Brasília: MA/SNI/DNMET, 1992. 84 p.

CARVALHO, J. de A. et al. Efeitos de diferentes níveis de déficit hídrico e de doses de nitrogênio sobre a produção do pimentão. Engenharia Agrícola, Jaboticabal, v. 21, n. 3, p. 262-269, 2001.

COMISSÃO DE FERTILIDADE DO SOLO DE MINAS GERAIS. Café. In: __ Recomendações para uso de corretivos e fertilizantes em Minas Gerais: 5ํaproximação. Viçosa, 1999. p. 289-302.

COSTA, W. M.; GONÇALVES, W.; FAZUOLI, L. C. Produção de café Mundo Novo em porta-enxerto de Coffea canephora em área infestada com Meloidodogyne incognita raça1. Nematologia Brasileira, Piracicaba, v. 15, p. 43-50, 1991.

FAHL, J. I. et al. Enxertia de Coffea arabica sobre Coffea canephora e Coffea congensis na nutrição mineral, crescimento e produção. Bragantia, Campinas, v. 57, n. 2, p. 297-312, 1998.

FAZUOLI, L. C. Genética e melhoramento do cafeeiro. In: RENA, A. B. et al. (Eds.). Cultura do cafeeiro: fatores que afetam a produtividade. Piracicaba: POTAFOS, 1986, p. 87-113.

FAZUOLI, L. C.; COSTA, W. M.; BORTOLETTO, N. Efeitos do porta-enxertos LC 2258 de Coffea canephora resistente a Meloidogyne incognita, no desenvolvimento e produção iniciais de dois cultivares de Coffea arabica. In: CONGRESSO BRASILEIRO DE PESQUISAS CAFEEIRAS, 10., 1983, Poços de Caldas. Anais... Rio de Janeiro: MIC/IBC, 1983. p. 113-115.

FAZUOLI, L. C. et al. Tolerância de cafeeiros ao nematóide Meloidogyne incognita em condições de campo. In: CONGRESSO BRASILEIRO DE PESQUISAS CAFEEIRAS, 6., 1978, Ribeirão Preto. Resumos... Rio de Janeiro: IBC-GERCA, 1978. p. 246-248.

FERREIRA, D. F. Análises estatísticas por meio do Sisvar para Windows 4.0. In: REUNIÃO ANUAL DA REGIÃO BRASILEIRA DA SOCIEDADE INTERNACIONAL DE BIOMETRIA, 45., 2000, São Carlos. Anais... São Carlos: UFSCar, 2000. p. 255-258.

FIGUEIREDO JÚNIOR, W. P. Plantio de mudas de cafeeiro nas entrelinhas da lavoura adultas. 1999. 44 p. Dissertação (Mestrado em Fitotecnia) - Universidade Federal de Lavras, Lavras, 1999.

GERVÁSIO, E. S. Efeito de diferentes lâminas de água no desenvolvimento do cafeeiro (Coffea arabica L.) na fase de inicial de formação da lavoura. 1998. 58p. Dissertação (Mestrado em Engenharia Agrícola) Universidade Federal de Lavras, Lavras, 1998.

MATIELLO, J. B. et al. Siriema 842 material promissor, com resistência múltipla (Ferrugem e Bicho mineiro) e boa produtividade. In: CONGERSSO BRASILEIRO DE PESQUISAS CAFEEIRAS, 26., 2000, Marília. Anais... Marília: MAPA $\backslash P R O C A F E ́$, 2000. p. 51-52.

OMETTO, J. C. Bioclimatologia vegetal. São Paulo: Ceres, 1981. 425 p.

SOUZA, C. A. S. et al. Produção de mudas de cafeeiro enxertados. Lavras: UFLA, 2002. não paginado. (Boletim de extensão).

TOMAZIELLO, R. A. et al. Café Arábica: cultura e técnica de produção. Campinas: IAC, 2000. 82 p. (Boletim técnico, 187).

VILLAIN, L.; MOLINA, A.; ANZUETO, F. Uso del injerto y nematicida para el control del nematodo lesionador (Pratylenchus). In: ASSOCIATION NACIONAL DEL CAFÉ. Notas técnicas de la caficultura. Guatemala: Anacafé, [1995?]. 